\title{
MicRomorfología y ESTRUCTURA DE LOS FRUTOS EN BULBOSTYLIS (Cyperaceae) y su VAlor sistemático en las especies de AMÉrica AUSTRAL
}

\author{
MARÍA GABRIELA LÓPEZ1 y ANA MARIA GONZALEZ $Z^{1,2}$
}

\begin{abstract}
Summary: Micromorphology and structure in fruits of Bulbostylis (Cyperaceae) and their systematic value in Southern America species. The genus Bulbostylis Kunth includes about 150 species that inhabit tropical and subtropical areas worldwide. In Bulbostylis, as in other kinds of sedges, the exomorphology of fruits is one of the steadiest characters for infrageneric classification. This research was focused on evaluating achene micromorphology in twenty Bulbostylis species of Southern America (Argentina, Chile, Paraguay, Uruguay and Paraná, Santa Catarina and Rio Grande do Sul in Brazil). Based on studies with optical and scanning electron microscopy, several groups are proposed, considering the micromorphology of the achenes and presence and type of silicophytoliths. Chemical microanalysis of fruits with EDX/MEB was also performed. The description system based on exomorphological characters, applicable to fruits and seeds, is updated.
\end{abstract}

Key words: Southern America, anatomy, achenes, Bulbostylis, Cyperaceae, SEM/EDX, micromorphology.

Resumen: El género Bulbostylis Kunth incluye aproximadamente 150 especies que habitan zonas tropicales y subtropicales en todo el mundo. En Bulbostylis, al igual que en otros géneros de Ciperáceas, la exomorfología de los frutos es uno de los caracteres más estables para la clasificación infragenérica. En este trabajo se dan a conocer la micromorfología y estructura de los frutos de Bulbostylis para veinte especies de América Austral, representadas en Argentina, Brasil (Paraná, Santa Catarina y Rio Grande do Sul), Chile, Paraguay y Uruguay. En base a estudios con microscopía óptica y electrónica de barrido se proponen agrupamientos, teniendo en cuenta la micromorfología de los aquenios así como la presencia y tipo de silicofitolitos. También se realizan microanálisis químicos de los frutos con EDX/ MEB. Se actualiza el sistema de descripción basado en caracteres exomorfológicos, aplicable a frutos y semillas.

Palabras clave: América Austral, anatomía, aquenios, Bulbostylis, Cyperaceae, EDX/MEB, micromorfología.

\section{INTRODUCCIÓN}

El género Bulbostylis Kunth incluye aproximadamente 150 especies que habitan zonas tropicales y subtropicales en todo el mundo. Algunas especies llegan a zonas templadas, siendo el límite sur de distribución en América los $42^{\circ} \mathrm{S}$. El género tiene dos importantes centros de diversidad: África y América del Sur (especialmente el centro

1 Facultad de Ciencias Agrarias. Sto. Cabral 2131. Corrientes, Argentina. mglopez2000@yahoo.com.ar

2 Instituto de Botánica del Nordeste, UNNE-CONICET. Sto. Cabral 2131. Corrientes, Argentina. anitama39@ gmail.com de Brasil). La mayoría de las especies se encuentran en hábitats abiertos, tales como las sabanas, con suelos arenosos y en algunos casos húmedos en parte del año (López, 2012).

En la mayoría de los géneros de Cyperaceae la exomorfología de los frutos es uno de los caracteres más estables para la clasificación infragenérica. Ejemplos de estudios que demuestran el valor taxonómico de la exomorfología de los frutos dentro de la familia son los realizados en especies de Bolboschoenus (Ascherson) Palla (Browning et al. 1997), Carex L. (Walter, 1975; Toivonen \& Timonen, 1976; Raymond \& Wujek 1983; Wujek \& Menapace, 1986; Menapace \& Wujek 1987; Standley, 1987, 1990), Cyperus L. (Denton, 1983; 
Lye, 1983; López \& Matthei 1995; Araújo \& Longhi-Wagner, 1997; Hefler \& Longhi-Wagner, 2008), Eleocharis R. Brown (Menapace, 1991; 1993), Eriophorum L. (Schuyler, 1971) Fimbristylis Vahl (Wujek et al. 1994; Menapace et al. 2003), Rhynchospora Vahl (Ragonese et al. 1984; Strong, 2006), Scirpus L. (Schuyler, 1971) y Scleria Bergius (Wujek et al. 2001). En Bulbostylis también la exomorfología del fruto es uno de los caracteres de interés taxonómico usado con mayor frecuencia en la delimitación interespecífica (Goetghebeur, 1984; Goetghebeur \& Coudijzer, 1984; Prata et al. 2008). Sin embargo, dentro del género, los estudios relacionados con el fruto han estado restringidos a ciertos aspectos morfológicos como el contorno, espesor del mesocarpio y endocarpio, y a caracteres micromorfológicos como el diseño de las células de la superficie, presencia o ausencia de cuerpos de sílice. La mayoría de estos estudios fueron realizados exclusivamente con microscopía electrónica de barrido, y en algunos casos se analizaron frutos inmaduros. En el trabajo de Prata et al. (2008), realizado para especies de Brasil, estos caracteres carpológicos fueron relacionados con el tipo de inflorescencia.

La presencia de sílice en células de las Cyperaceae se conoce desde 1872 según Mehra \& Sharma (1965), carácter estudiado también por Metcalfe (1971), Schuyler (1971) y Bertoldi de Pomar (1975), entre otros. La particular forma de cono y superficie lisa de los silicofitolitos caracteriza a las especies de esta familia según Piperno (1988). Ollendorf (1992) ofrece la mejor compilación para la familia, aunque estudia solo dos especies de Bulbostylis.

En 2010, Gonzalez y López estudiaron la anatomía y ontogenia del fruto de Bulbostylis capillaris (L.) C.B. Clarke, sensu Barros (B. communis M.G. López \& D. Simpson) y $B$. major Palla $[=B$. sphaerolepis (Boeck.) Beetle], identificando qué estructura del pericarpio determina los diversos diseños de la superficie del aquenio. En dicho trabajo se constató que las tres capas de la pared carpelar se diferencian en epicarpio, mesocarpio y endocarpio, sin cambios en el número de estratos; el fruto maduro presenta esclereidas en el mesocarpio, mientras que el epicarpio puede o no formar cuerpos de sílice que impregnan las paredes tangenciales internas.

En Bulbostylis las especies son muy semejantes en su aspecto morfológico y en algunos casos muy difíciles de diferenciar si no se observa el fruto. En este estudio se realizó el análisis macro- y micromorfológico de los aquenios y el microanálisis de elementos químicos que constituyen la pared del fruto de 20 especies de Bulbostylis de América Austral, en un intento por delimitar agrupamientos taxonómicos basados en los caracteres exomorfológicos y anatómicos de los frutos que permitan establecer relaciones interespecíficas.

Para estandarizar la descripción de la epidermis o la superficie de una semilla el estudio más exhaustivo es el de Barthlott (1981), quién analizó con MEB cerca de 5000 especies y estableció la significancia de este carácter en estudios taxonómicos. Esta terminología se usó y se amplió en el presente análisis de los frutos de Bulbostylis, generando un sistema más completo, factible a ser aplicado a la descripción de diásporas de otros taxones.

\section{Materiales y Métodos}

Se seleccionaron frutos de 20 especies de Bulbostylis de América Austral de ejemplares del Herbario "Carmen L. Cristóbal" del Instituto de Botánica del Nordeste, Corrientes, Argentina (CTES), y un ejemplar del Herbario Fundación Miguel Lillo (LIL). Los materiales utilizados y su procedencia se encuentran en el Anexo I. De cada especie se tomaron frutos maduros de entre dos y cinco ejemplares de diferentes localidades.

Microscopía electrónica de barrido (MEB): para este análisis diez frutos de cada especie se dividieron en dos grupos: a la mitad se le realizó un pretratamiento en el cual se extrajo la pared periclinal externa siguiendo la técnica de Schuyler (1971). Para ello los frutos se colocaron en una solución de anhídrido acético y ácido sulfúrico (9:1), seguido de 2-3 lavados con centrífuga durante 5 minutos, para la remoción total de las impurezas. Al segundo grupo de frutos no se le retiró la pared periclinal externa. Los frutos de ambos grupos fueron metalizados con Oro para la observación con MEB modelo JEOL LV 5800 del Servicio de Microscopía de la UNNE, Corrientes.

La detección del contenido cualitativo de sílice y su distribución en la superficie del fruto se realizó 


\section{G.López y A. M. Gonzalez - Frutos de Bulbostylis en las especies de América austral}

con análisis EDX (Espectroscopía por Energía Dispersiva de Rayos-X), técnica analítica usada para caracterización química por medio de EDX/ MEB. Para ello se usaron \pm 6 frutos maduros por especie, los que se montaron sin pretratamiento en una platina de cobre y se metalizaron con Oro. Se usó un Microscopio Electrónico de Barrido marca Philips modelo SEM 505 con Digitalizador de Imagen Soft Imaging Sistem ADDA II y detector de EDS marca EDX de ventana ultrafina (UTW), dispersivo en energías, que permite determinar elementos livianos de $Z>5$ (a partir de boro) a $20 \mathrm{KV}$; las condiciones del mapeo fueron spot 500, a igual magnitud que la imagen (CINDECA, CONICET-Universidad Nacional de La Plata). Las dos formas distintas de presentación cualitativa de datos que provee el EDX son Espectro, que identifica los elementos presentes en la microárea analizada y Mapeo de puntos que muestra la localización espacial de los elementos presentes en la zona de análisis.

Microscopía óptica (MO): para observaciones de las células del pericarpio se procedió al macerado de los frutos usando solución de Schulze (Parr et al., 2001). Las observaciones se realizaron en microscopio óptico Leica MZ6 con luz polarizada y sistema de captura digital de imágenes. La identificación del sílice se realizó con fenol que tiñe de color rosa pardo dicho elemento (Johansen, 1940).

Para la descripción de los frutos de Bulbostylis se siguió la terminología de Lindley (1951), Barthlott (1981) y Lye (1983, 2000). También se utilizó el trabajo de Stace (1965) para describir la ondulación de las paredes epidérmicas y el de Barthlott et al. para nomenclatura de ceras (1989). Para el presente estudio se siguieron las reglas del "International Code for Phytolith Nomenclature" (ICPN WORKING GROUP, 2005).

\section{Resultados}

\section{Estructura morfo-anatómica del aquenio}

Los aquenios de las especies estudiadas de Bulbostylis se caracterizan por ser en general obcónicos a obovoides, trígonos (Fig. 1 A). Su tamaño es pequeño, oscila desde 0,6 a $1,5 \mathrm{~mm}$ de largo x 0,5 a 1,4 mm de ancho. Presentan un estilopodio apical (Figs. 1 A; 2 A,D,G,J,M,P,S; 3
A,D,G,J; 4 A,D,G,J,M,P,S,V). Las particularidades de cada especie se muestran en la Tabla 1.

Anatómicamente el pericarpio de los aquenios de Bulbostylis está formado de tres capas uniestratificadas: epicarpio, son células tabulares, de paredes delgadas, celulósicas (Fig. 1A, C); mesocarpio, constituido por esclereidas dispuestas longitudinalmente en el fruto, con paredes externas sinuosas a profundamente crestadas (Fig. 1B, K-P), y endocarpio, células alargadas pero dispuestas transversalmente en relación al eje mayor del fruto y en ángulo recto con respecto a las esclereidas del mesocarpio (Fig. $1 \mathrm{~B}$ ).

Para describir la superficie de los aquenios se consideró la clasificación de Barthlott (1981), la cual fue adaptada para el género en estudio:

Macroescultura: describe la topografía general en vista superficial; no se tiene en cuenta el diseño de cada célula en particular sino el arreglo de las diversas capas y su apariencia en toda la superficie del fruto. Barthlott (1981) no consideró esta categoría en su clasificación. Solo menciona "arregement of epidermal cell" o "celular patterns". En Bulbostylis la macroescultura del fruto varía de más o menos lisa (Fig. $2 \mathrm{U}$ ) a punteada (Fig. 3 D, G; 4 P, V), ondulada o crestada (Fig. 2 J, M), con elevaciones de diversas alturas y extensión. Cuando se describen ondas o crestas, están siempre dispuestas transversalmente en el fruto y están formadas por la superficie de las esclereidas del mesocarpio (Fig. 2 A). En el caso de los frutos punteados, los silicofitolitos son tan evidentes que se observan exomorfológicamente (Fig.4 P).

Escultura primaria: básicamente es la forma de las células (epidérmicas) en vista superficial (Figs. 2-4). Este carácter está influenciado por cuatro microcaracteres:

Contorno de las células: varía entre isodiamétricas, poligonales a alargadas (Figs. 2-4).

Paredes anticlinales: se analiza su grado de sinuosidad. Barthott (1981) describe este carácter exclusivamente para la pared anticlinal externa, es decir en vista superficial. Los límites de las células varían de paredes rectas (Fig. $2 \mathrm{~B}, \mathrm{H}, \mathrm{N}, \mathrm{Q}, \mathrm{U}$ ) a onduladas, en este caso se usaron los siguientes descriptores: "()", "C", "V" y " $\Omega$ " (omega), (Figs. 1 C, 2-4). En Bulbostylis se pudo observar además, debido a los tratamientos de eliminación de la pared tangencial externa, que la pared anticlinal interna siempre es ondulada (Fig. 1 D-H). 
Bol. Soc. Argent. Bot. 52 (1) 2017
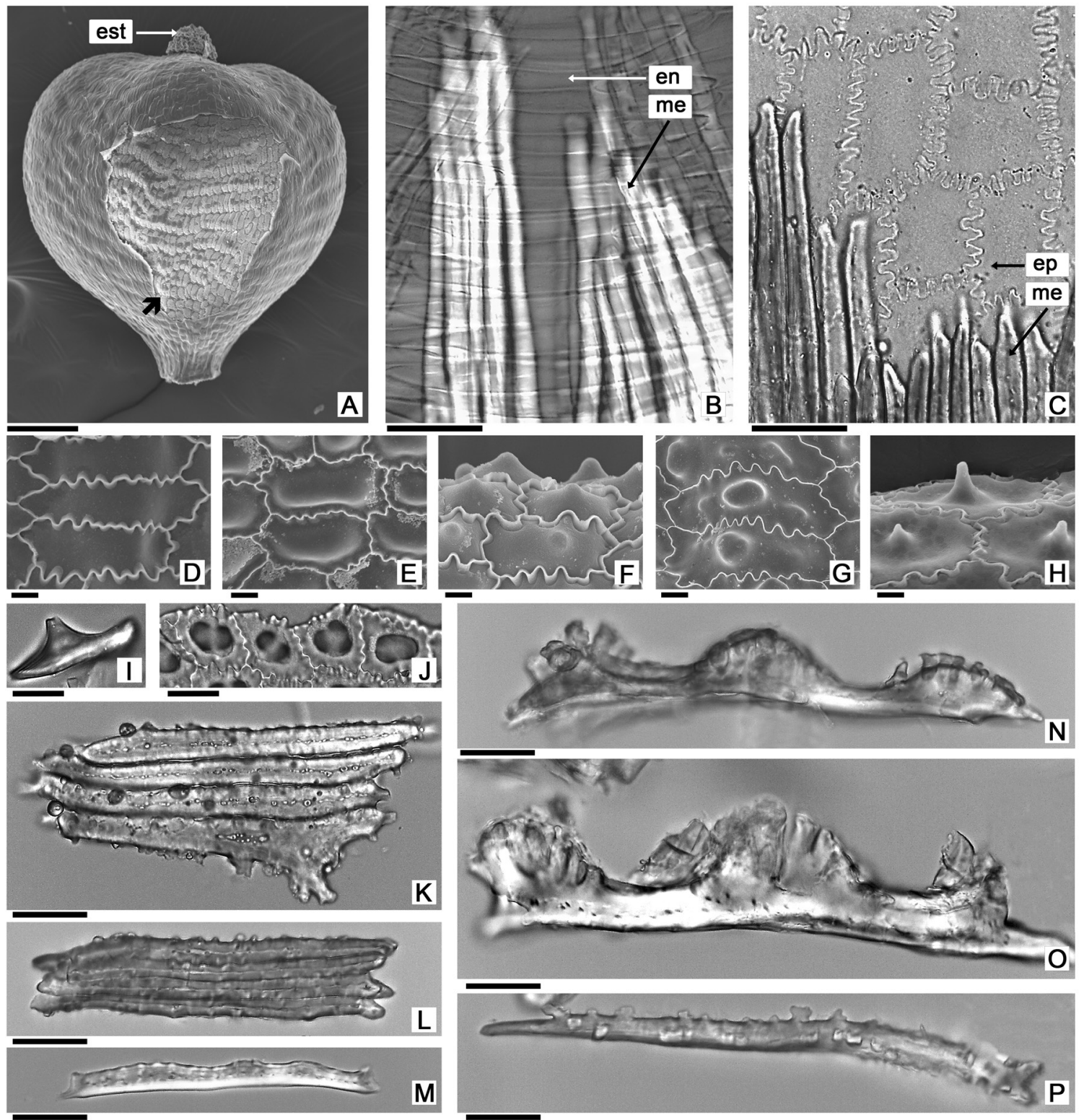

Fig. 1. Estructura morfo-anatómica de los aquenios. Detalles de las células del epicarpio y esclereidas del mesocarpio. A: B. scabra, fruto con estilopodio (est) y epicarpio parcialmente desprendido, (flecha, foto con MEB). B-C: pericarpio macerado (MO), B: B. communis, endocarpio (en) y mesocarpio (me). C: B. hirtella, mesocarpio (me) y epicarpio (ep). D-H: epicarpio acetolizado sin pared externa (MEB). D: B. aspera, sin cuerpos de sílice. E: B. jacobinae, silicofitolitos globosos. F: B. juncoides, silicofitolitos cónicos de ápice redondeado; G: $B$. consanguinea, silicofitolitos cónicos con múltiples ápices. H-I: $B$. loefgrenii, silicofitolitos cónicos de ápice agudo, I: silicofitolito macerado, MO. J: B. sphaerocephala vista superficial de epicarpio con silicofitolitos con múltiples ápices. K-P: esclereidas del mesocarpio (macerado, MO). K: $B$. scabra. L: $B$. jacobinae. M: B. hirtella. N: B. juncoides. O: B. sphaerolepis. P: B. subtilis. Escalas= A: $200 \mu \mathrm{m}, \mathrm{B}-\mathrm{C}, \mathrm{K}-\mathrm{P}$ : $25 \mu \mathrm{m}, \mathrm{D}-\mathrm{J}: 10 \mu \mathrm{m}$. 
M. G.López y A. M. Gonzalez - Frutos de Bulbostylis en las especies de América austral
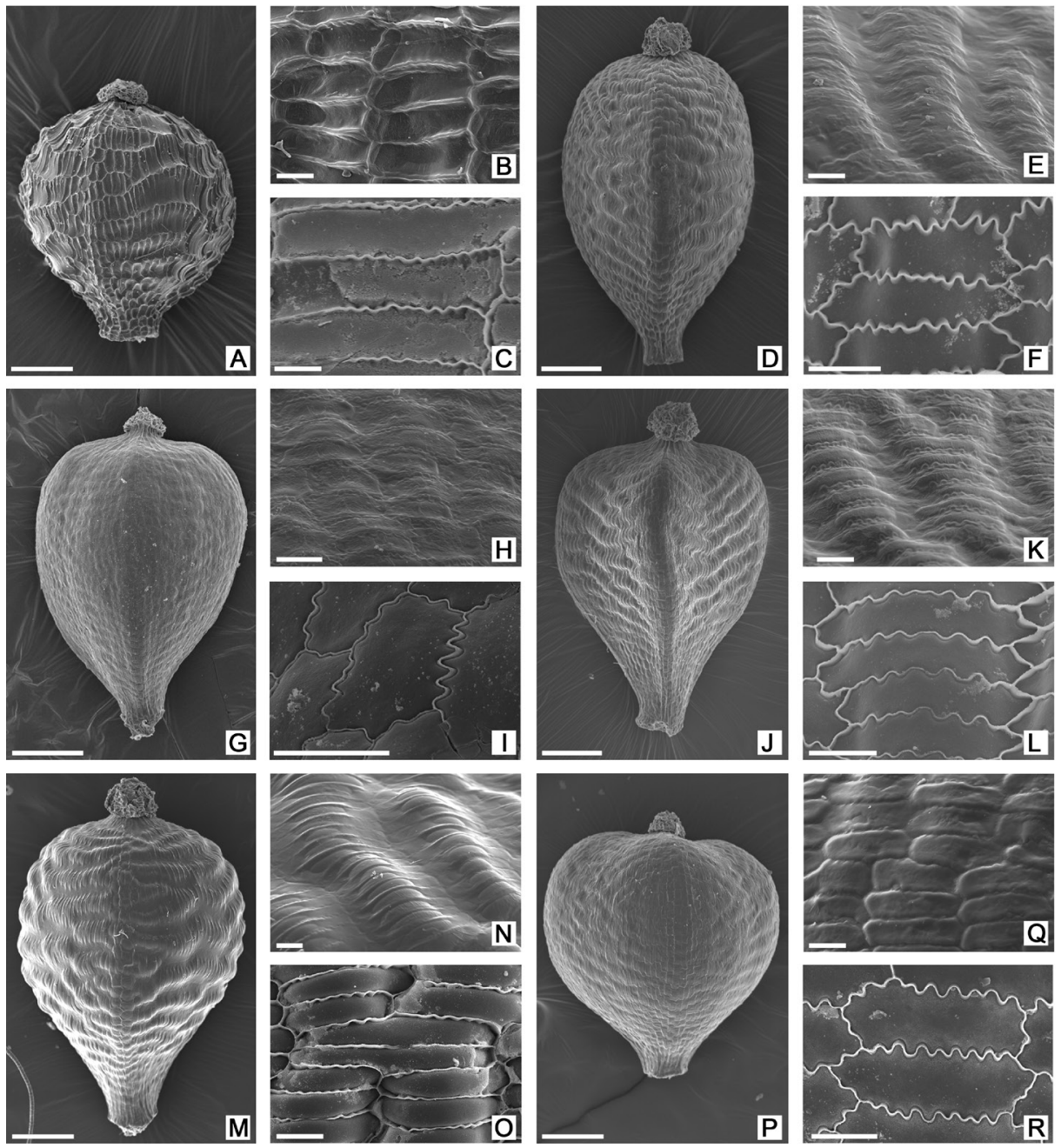

M
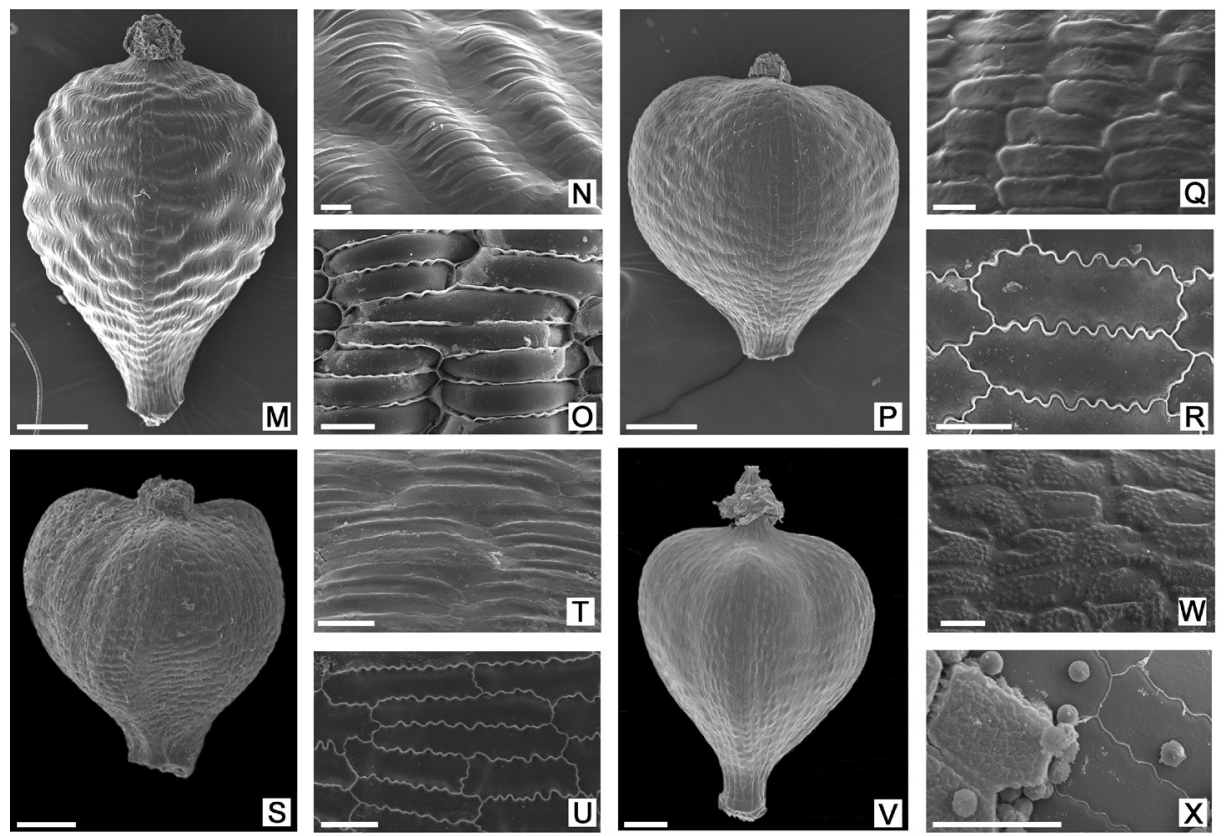

Fig. 2. Frutos de Bulbostylis grupo 1, microfotografías con MEB, en cada especie se ilustra fruto completo (izquierda), detalle de la pared periclinal externa sin tratamiento (arriba) y detalle del epicarpio donde el tratamiento químico eliminó la pared periclinal externa (abajo). Subgrupo 1a: A-C: B. funckii. Subgrupo 1b: D-F: B. aspera. G-I: B. brevifolia. J-L: B. contracta. M-O: B. rugosa. P-R: B. scabra. S-U: B. paradoxa. $\mathrm{V}-\mathrm{X}: \mathrm{B}$. communis, $\mathrm{X}$ : detalle donde se eliminó parcialmente la pared externa del epicarpio. Escalas= A,D,G,J,M,P,S: $200 \mu \mathrm{m}$, restantes: $25 \mu \mathrm{m}$. 

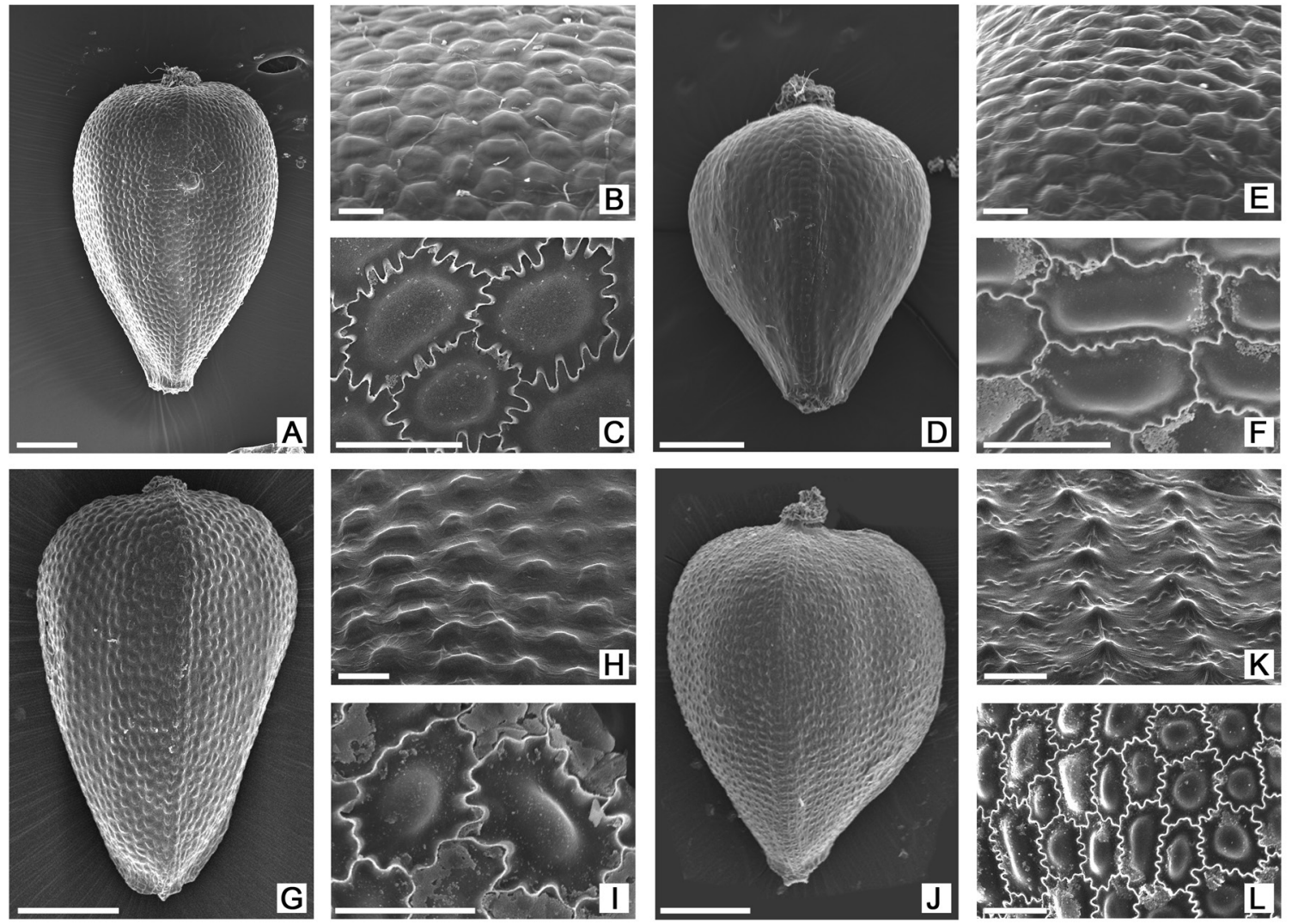

Fig. 3. Frutos de Bulbostylis grupo 2, microfotografías con MEB, en cada especie se ilustra fruto completo (izquierda), detalle de la pared periclinal externa sin tratamiento (arriba) y detalle del epicarpio donde el tratamiento químico eliminó la pared periclinal externa (abajo). A-C: B. amambayensis. D-F: B. jacobinae. G-I: B. junciformis. J-L: B. sphaerocephala. Escalas= A,D,G,J: $200 \mu \mathrm{m}$, restantes: $25 \mu \mathrm{m}$.

Relieve de los límites celulares: en vista superficial, la unión de las paredes periclinales de células vecinas (sin tratamiento de remoción de pared periclinal externa) pueden ser imperceptibles, lisos, elevados o acanalados (Figs. 2-4).

Curvatura de la pared periclinal externa: con una amplia variación desde cóncava a plana, convexa o con formas o proyecciones especiales como cónicas o mamiliformes. En Bulbostylis, esta pared está influenciada además por la estructura tridimensional de toda la célula del epicarpio; por ejemplo los cuerpos de sílice que impregnan la pared tangencial interna alcanzan la pared externa y determinan la existencia de verdaderas papilas de formas hemisféricas (Fig. 3) a cónicas (Fig. 4). En otros casos, las excrecencias de la pared de las esclereidas del mesocarpio forman crestas $\mathrm{u}$ ondulaciones, el epicarpio se adapta a este diseño y por lo tanto se aprecia en vista superficial (Fig. 1 K-P, 2).

Escultura secundaria: representada por la micro-ornamentación de la pared externa de las células, cuyo origen puede ser inclusiones cuticulares o subcuticulares, presencia de paredes con engrosamientos diferenciales o variaciones superficiales producto de contenidos celulares (granos de almidón por ejemplo, Fig. 2 U).

Escultura terciaria: de acuerdo a Barthlott (1981) está determinado por la presencia de secreciones epicuticulares. Esta escultura sólo fue encontrada en $B$. sphaerolepis donde se observan pequeños granos de cera (Fig. $4 \mathrm{H}^{*}$ ). 


\section{G.López y A. M. Gonzalez - Frutos de Bulbostylis en las especies de América austral}

Tabla 1. Análisis exomorfológico de los frutos maduros.

\begin{tabular}{|c|c|c|c|c|}
\hline Taxones & Color & Forma & Medida (mm) & Forma del estilopodio \\
\hline B. amambayensis & plomizo & obovoide & $1-1,5 x \pm 0,84$ & umbonado \\
\hline B. aspera & fumoso & oblongo a obovoide & $1,2-1,3 \times 0,75$ & plano \\
\hline B. brevifolia & álbido & obovoide & $0,75-1,2 \times 0,6-0,7$ & cónico \\
\hline B. communis & álbido & piriforme & $0,75-1 \times 0,75$ & cónico \\
\hline B. consanguinea & pardo & obcónico & $1,25 \times 0,75$ & trilobado \\
\hline B. contracta & álbido & obcónico & $1 \times 0,75$ & verruciforme \\
\hline B. funckii & pardo & redondeado & $0,75-0,8 \times 0,65$ & umbonado \\
\hline B. guaglianoneae & cinéreo & oblongo a obovoide & $1,25-1,5 \times 0,8-1$ & umbonado \\
\hline B. hirtella & pardo & obcónico & $0,75-0,8 \times 0,75$ & verruciforme \\
\hline B. jacobinae & pardo & obcónico & $0,6-0,9 \times 0,5$ & cónico \\
\hline B. junciformis & ocráceo & obcónico & $0,8-1 \times 0,5-0,6$ & plano \\
\hline B. juncoides & pardo & obovoide & $1-1,2 \times 0,8-1$ & plano \\
\hline B. loefgrenii & álbido & obovoide & $1,5-1,8 \times 0,8-1,2$ & cilíndrico \\
\hline B. paradoxa & negro azabache & cordiforme & $1,2-1,8 \times 1-1,4$ & trilobado \\
\hline B. rugosa & fumoso & obovoide & $1-1,4 \times 1$ & cilíndrico \\
\hline B. scabra & ocráceo & cordiforme a obovide & $0,75-1 \times 0,8-1$ & umbonado \\
\hline B. sphaerocephala & plomizo & obcónico & $0,75-1 \times 0,50-0,75$ & verruciforme \\
\hline B. sphaerolepis & pardo & obovoide & $1-1,5 \times 1-1,25$ & cilíndrico \\
\hline B. stenocarpa & plomizo & oblongo & $1,1-1,3 \times 0,5-0,8$ & umbonado \\
\hline B. subtilis & ocráceo & obovoide & $1-1,25 \times 0,75$ & plano \\
\hline
\end{tabular}

En la tabla 2 se listan los caracteres de la macroescultura, escultura primaria (discriminando los microcaracteres evaluados) y la escultura secundaria de cada especie analizada.

\section{Microanálisis de los frutos mediante EDX/MEB}

En los espectros de las especies de Bulbostylis aquí estudiadas se observa que el sílice está siempre acompañado por otros elementos químicos que son: carbono, oxígeno, potasio (Fig. 5). Además se encontraron presentes y en forma variable elementos como: magnesio ( $B$. aspera, $B$. brevifolia, B. contracta, B. guaglianoneae, $B$. junciformis, B. loefgrenii y $B$. sphaerolepis); sodio (B. aspera, B. brevifolia, B. hirtella y $B$. scabra) y calcio (B. amambayensis, B. funckii y $B$. stenocarpa).

La distribución del silicio en la superficie del fruto resultó uniforme y no se encontraron diferencias entre los frutos que forman cuerpos de sílice y los que no lo forman (Fig. 6). Bulbostylis scabra (Fig. $6 \mathrm{~K}-\mathrm{L}$ ) tiene un fruto que no forma cuerpos de sílice y cuya microtopografía posee ondulaciones horizontales y células alargadas, en el mapeo detallado se puede ver que la distribución del sílice acompaña a esta superficie.

\section{Discusión}

Los frutos de Bulbostylis son en su mayoría obovoides y obcónicos, y en menor medida cordiformes, oblongos o piriformes. El color de los frutos maduros varía en los tonos de grises, negro, marrón siendo muy raro el blanco, coincidiendo con Lye (2000) que establece estos colores como los más frecuentes en los frutos de las Cyperaceae. Todos los aquenios estudiados son trígonos, el tamaño va desde 0,6 a $1,5 \mathrm{~mm}$ de largo x 0,5 a 1,4 mm de ancho. El estilopodio adopta una gran variabilidad de formas: 
Bol. Soc. Argent. Bot. 52 (1) 2017
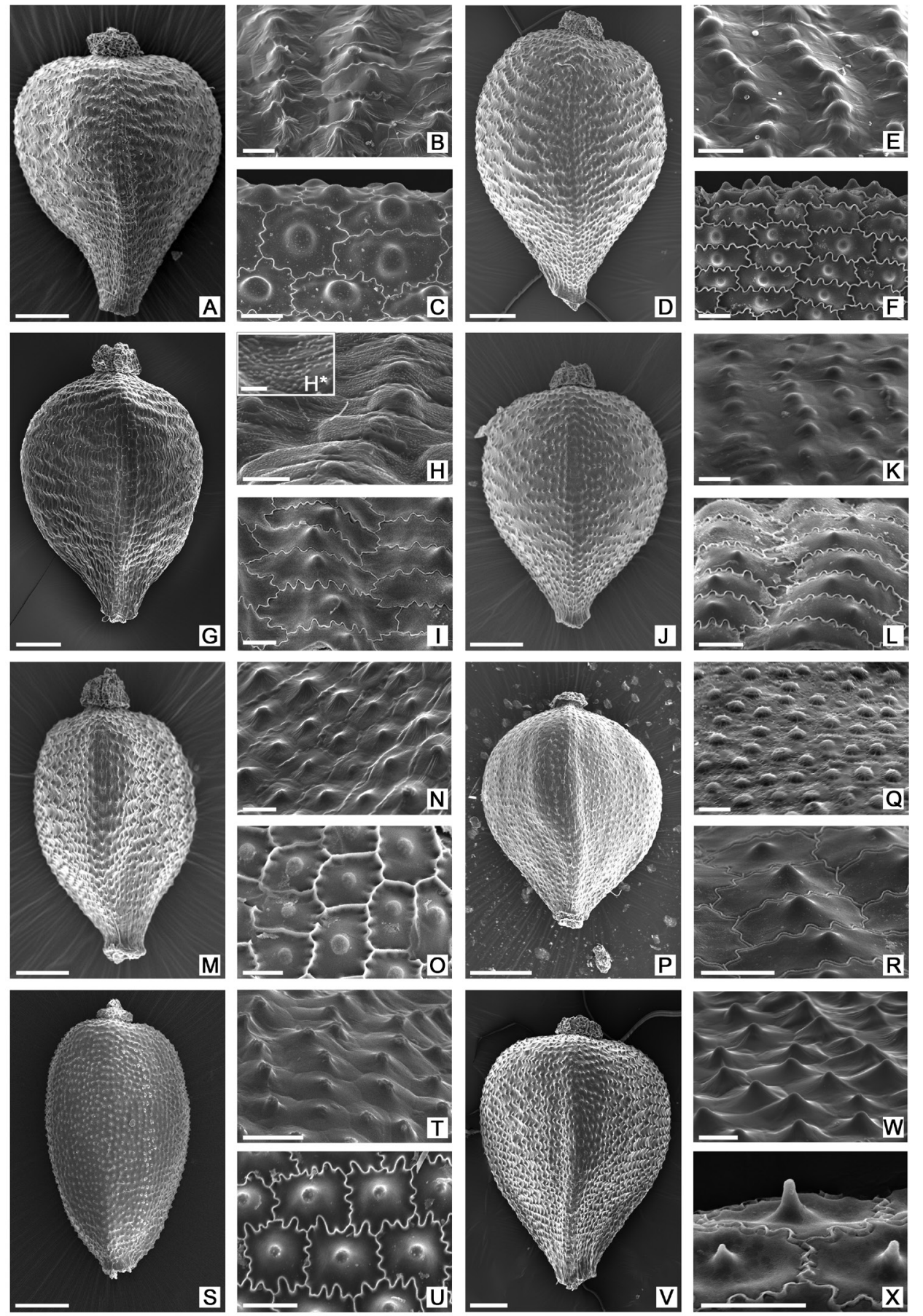

Fig. 4. Frutos de Bulbostylis grupo 3, microfotografías con MEB, en cada especie se ilustra fruto completo (izquierda), detalle de la pared periclinal externa sin tratamiento (arriba) y detalle del epicarpio donde el tratamiento químico eliminó la pared periclinal externa (abajo). Subgrupo 3a: A-C: B. consanguinea. D-F: B. juncoides. G-I: $B$. sphaerolepis, $\mathrm{H}^{*}$ : detalle de las ceras epicuticulares. J-L: B. subtilis. Subgrupo 3b: M-O: B. guaglianoneae. P-R: B. hirtella. S-U: B. stenocarpa. Subgrupo 3c: V-X: B. loefgrenii. Escalas= A,D,G,J,M,P,S: $200 \mu \mathrm{m}, \mathrm{H}^{*}: 5 \mu \mathrm{m}$, restantes: $25 \mu \mathrm{m}$. 


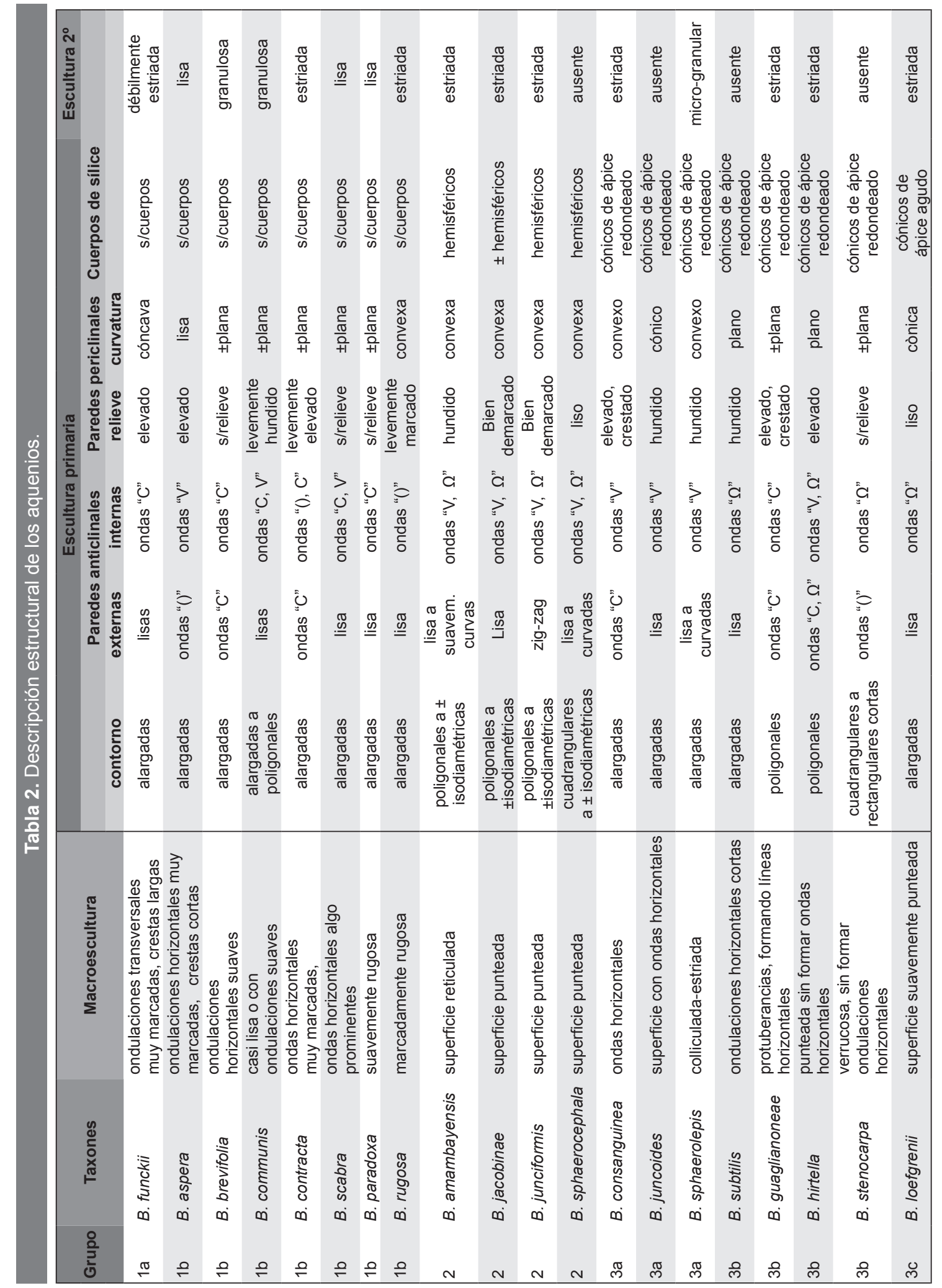


Bol. Soc. Argent. Bot. 52 (1) 2017

\section{B. amambayensis}

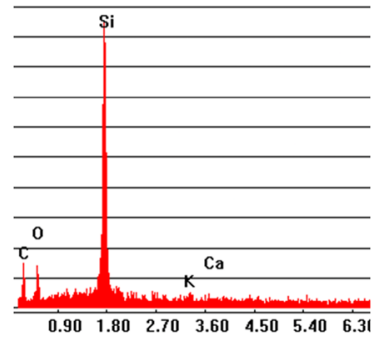

B. contracta

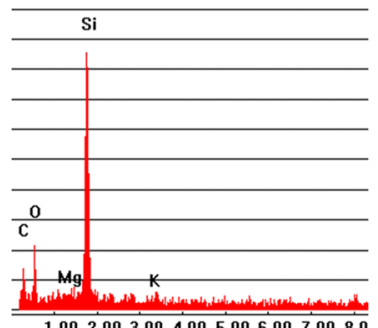

1.002 .003 .004 .005 .006 .007 .008 .0

\section{B. junciformis}

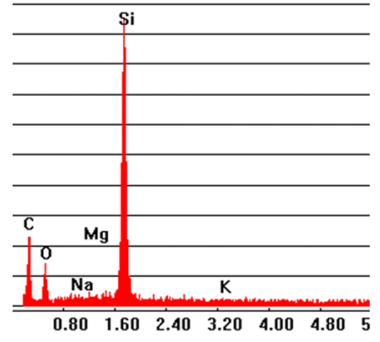

B. rugosa

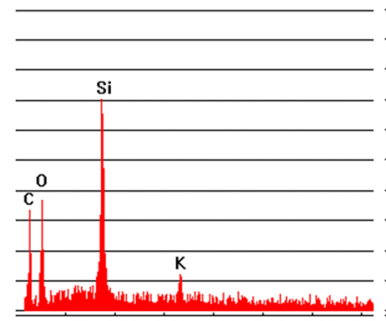

$\begin{array}{llllll}1.00 \quad 2.00 & 3.00 & 4.00 & 5.00 & 6.00 & 7.0\end{array}$
B. aspera

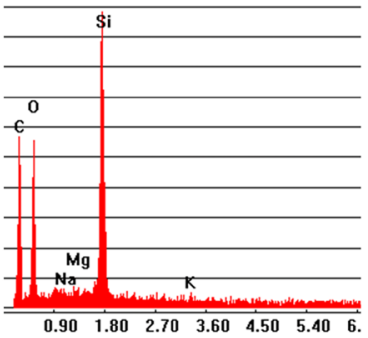

B. funckii

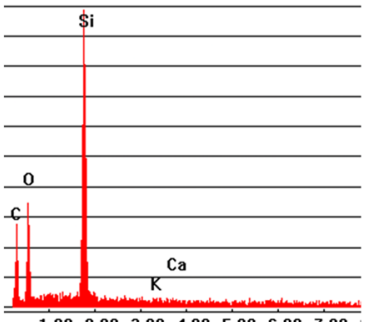

$1.00 \quad 2.00 \quad 3.00 \quad 4.00 \quad 5.00 \quad 6.007 .00$

$B$. juncoides

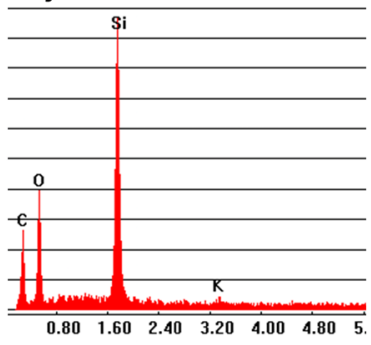

B. scabra

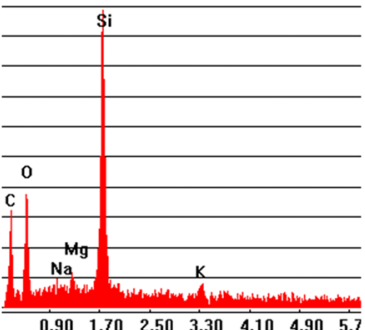

B. subtilis

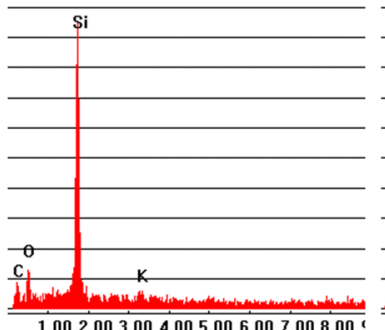

1.002 .003 .004 .005 .006 .007 .008 .00
B. brevifolia

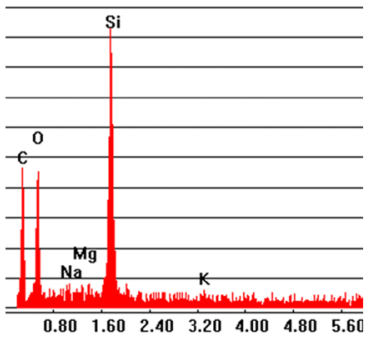

B. guaglianoneae

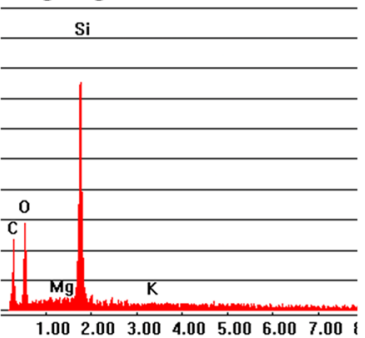

B. loefgrenii

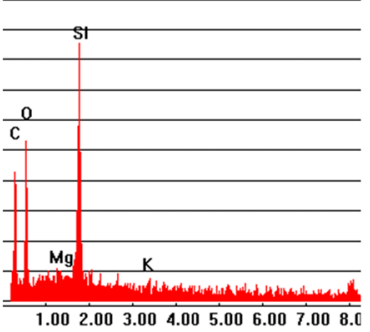

B. sphaerocephala

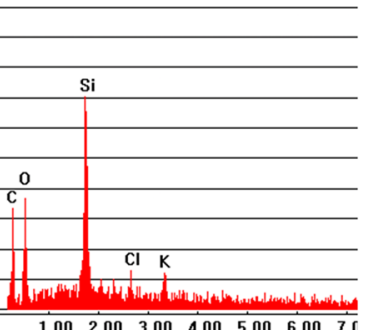

$\begin{array}{llllllll}1.00 & 2.00 & 3.00 & 4.00 & 5.00 & 6.00 & 7 .\end{array}$ B. stenocarpa

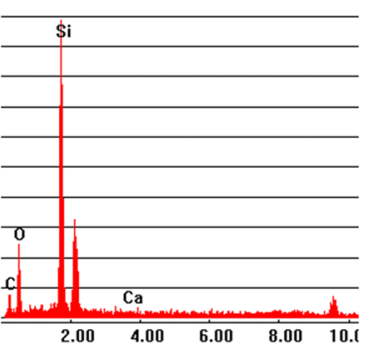

B. communis

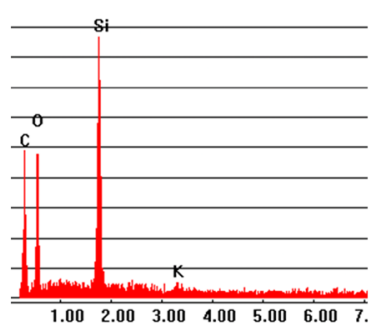

B. hirtella

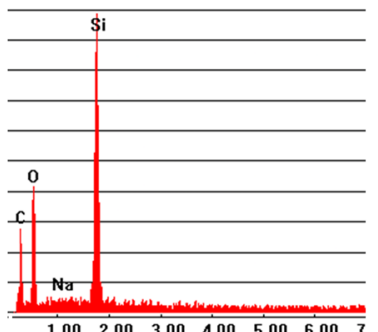

B. paradoxa

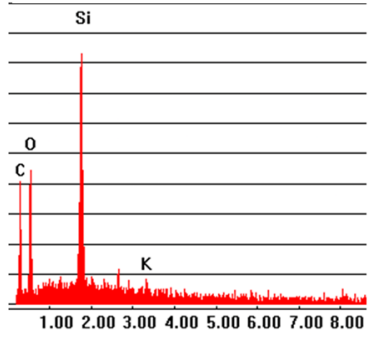

B. sphaerolepis

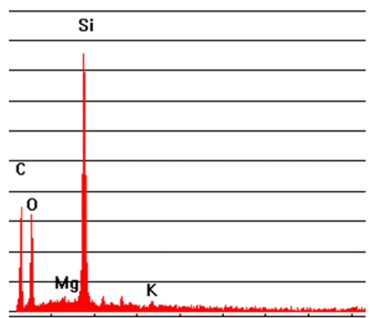

1.002 .003 .004 .005 .006 .007 .008 .0$$
\text { . }
$$

Fig. 5. Microanálisis de los frutos de Bulbostylis mediante EDX/MEB. 

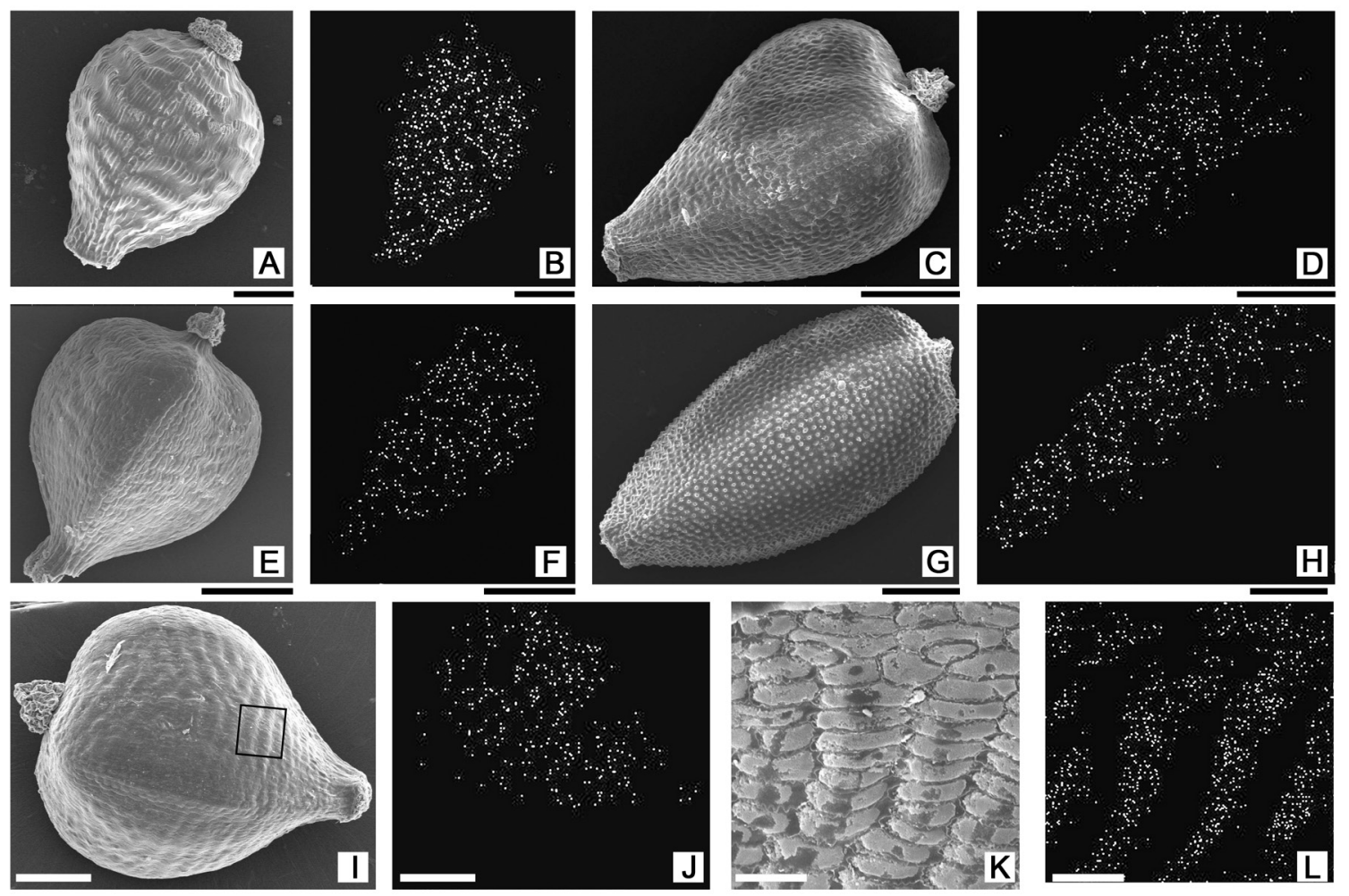

Fig. 6. Mapeo de puntos mediante el estudio correlativo EDX/MEB mostrando la localización espacial del silicio presente en una de las caras del aquenio. A-B: B. funckii; C-D: B. sphaerocephala; E-F: B. communis; G-H: B. stenocarpa; I-L: B. scabra; A-J: mapeo de fruto completo, K-L: detalle del sector indicado en I. Escalas $=\mathrm{A}-\mathrm{J}: 200 \mu \mathrm{m}, \mathrm{K}-\mathrm{L}: 50 \mu \mathrm{m}$.

umbonado, plano, cónico, trilobado, verruciforme y cilíndrico.

Barthlott (1981) analizó con MEB caracteres de la epidermis completa de cerca de 5000 especies, incluyendo la de las semillas y estableció la significancia de este análisis en estudios taxonómicos, aunque no especifica su uso en la descripción de frutos en particular. Este autor agrupó los caracteres epidérmicos en cuatro categorías, tres de las cuales fueron denominadas con el término esculturas, y listadas de primaria a terciaria, visibles con MEB y en niveles crecientes de magnificación.

La primera categoría de Barthlott (1981) fue indicada como "celular patterns" e incluye la distribución de diversos tipos celulares en la epidermis (como presencia de idioblastos, tricomas o estomas) y visible usualmente a bajos aumentos. En el presente estudio se amplió esta categoría y se la ubica en un nivel superior de ordenación que se denominó macroescultura, en el cual se incluye, además de los arreglos de células de la epidermis, a las distintas capas subepidérmicas que participan y determinan la topografía general de la superficie.

Grupos infragenéricos de Bulbostylis según las esculturas del fruto:

GRUPO 1: Frutos sin cuerpos de sílice (Fig. 2). Si bien el análisis EDX/MEB muestra la presencia de este elemento en todas las especies analizadas, se agrupó en esta categoría a los frutos de Bulbostylis caracterizados porque el sílice no forma cuerpos o estructuras definidas. El epicarpio posee células alargadas, siempre en relación al eje mayor que coincide con el eje longitudinal del fruto. Posee macroescultura con crestas $\mathrm{u}$ ondulaciones horizontales determinadas por las esclereidas del mesocarpio (Fig. $1 \mathrm{~A}$ ). 
Este grupo está formado por siete especies, que se pueden diferenciar en dos subgrupos:

Subgrupo 1a: En este subgrupo el epicarpio se caracteriza por sus paredes anticlinales externas lisas. Plataforma cóncava formada por la depresión de la pared periclinal externa del epicarpio y relieve elevado de las paredes anticlinales (Fig. 2 A-C). Solo B. funckii presenta este subtipo.

Subgrupo 1b: Las restantes especies: $B$. aspera, B. brevifolia, B. communis, B. contracta, $B$. paradoxa y $B$. scabra, se diferencian por la pared periclinal externa convexa (Fig. 2 D-V).

GRUPO 2. Frutos con sílice en forma de cuerpos globosos que ocupan casi toda la célula epidérmica, dejando un borde deprimido que acompaña al contorno de la célula. Estos silicofitolitos tienen forma redondeada o rectangular de bordes redondeados, dependiendo de la forma de la célula donde se encuentran, la superficie externa del cuerpo de sílice es convexa (Figs. 1 E, 3). La macroescultura es punteada, característica determinada por los silicofitolitos; las células del epicarpio tienen forma variable entre oblongas y más o menos isodiamétricas, pared anticlinales externas lisas a suavemente curvadas, a excepción de $B$. junciformis que se caracteriza por tener estas paredes en zig-zag y paredes anticlinales de relieve elevado.

GRUPO 3. Frutos con silicofitolitos conoidales (Fig. 4), la forma del ápice determina dos subgrupos:

Subgrupo 3a: la macroescultura posee ondulaciones transversales cortas y suaves, donde además cada célula tiene un silicofitolito en forma de cono, con ápice redondeado evidenciado en la cresta de la célula (Fig. 1 F, I). Células del epicarpio predominantemente alargadas. Dentro de este subgrupo se destacan $B$. subtilis y $B$. consanguinea porque al retirar la pared periclinal externa los silicofitolitos tienen ápices múltiples en algunas células (Fig. $1 \mathrm{G}, \mathrm{J}$ ).

Subgrupo 3b: solo B. loefgrenii se encuentra en este subgrupo. Esta especie presenta superficie suavemente punteada, causada por silicofitolitos de ápice agudo (Fig. $1 \mathrm{H}$ ).

En Bulbostylis el diseño de la superficie del fruto es resultado de la interacción entre la epidermis o epicarpio y mesocarpio. Las células epidérmicas influyen en la superficie a través de la presencia y forma de los silicofitolitos, mientras que las esclereidas determinan la presencia de ondulaciones o crestas. Esta topografía es visible bajo lupa y usualmente es referida en las descripciones taxonómicas del género Bulbostylis bajo denominaciones como punteada, reticulada, verrugosa, tuberculada o con protuberancias puntiformes (Goetghebeur, 1984; Goetghebeur \& Coudijzer, 1984; Prata et al. 2008; López, 2012), en estos casos se deben a la presencia de sílice en forma de cuerpos conspicuos o silicofitolitos; en otros casos los frutos se describen como rugosos, con ondas o líneas transversales (Goetghebeur, 1984; Goetghebeur \& Coudijzer, 1984; Prata et al. 2008; López, 2012), los estudios realizados aquí demostraron que estos tipos de pericarpio son el resultado de epidermis más las esclereidas del mesocarpio.

En las Ciperáceas y otras familias con aquenios es común el análisis estrictamente superficial, dada la importancia taxonómica del carácter y su facilidad de observación (Schuyler, 1971; Toivonen \& Timonen, 1976; Raymond \& Wujek 1983; Denton 1983; Goetghebeur, 1984; Goetghebeur \& Coudijzer, 1984; Wujek \& Menapace, 1986; Menapace \& Wujek, 1987; Waterway, 1990; Menapace, 1991 y 1993; Wujek et al. 1994; López \& Matthei, 1995; Menapace et al. 2003; Wujek et al. 2001; Prata et al. 2008). Si bien es cierto que en la mayoría de los casos el estudio de frutos o semillas se restringe a análisis superficiales con lupa o MEB y por lo tanto caracteres exclusivamente epidérmicos, a partir del presente estudio se destaca la importancia de un análisis anatómico y estructural que evidencie el verdadero origen del diseño superficialmente visible. Hay numerosos ejemplos en la bibliografía donde la interacción de estratos dérmicos y subepidérmicos es responsable del diseño de la superficie, no solo de frutos sino también en semillas, por ejemplo en las Turneráceas las semillas se describen como areoladas o crestadas y a través del estudio anatómico se revela que se debe a la relación o influencia recíproca entre las células de la exotesta y las esclereidas de la endotesta (Gonzalez \& Arbo, 2013).

La aplicabilidad de la clasificación ampliada en este trabajo se transfiere no solo al análisis de frutos secos sino también al de las semillas, donde es importante considerar la interacción entre los diversos estratos. 


\section{G.López y A. M. Gonzalez - Frutos de Bulbostylis en las especies de América austral}

Prata et al. (2008) analizaron la superficie del aquenio de 38 especies de Bulbostylis y determinaron tres patrones de ornamentación: uno sin cuerpos de sílice, denominado reticulado, donde el retículo se determina por las células epidérmicas; y dos diseños con cuerpos de sílice en toda la superficie: tuberculado (sin líneas transversales), y transversalmente rugoso (con arrugas más o menos prominentes). Este último patrón, según los autores (Prata et al. 2008) se debe a la organización de las células epidérmicas de cada especie; dato que se corrige con el presente estudio, donde se evidencia que el mesocarpio también participa en la formación de las crestas o arrugas.

La estructura primaria queda determinada básicamente por la forma de la epidermis en vista superficial y depende de una serie de caracteres celulares (contorno, curvatura de paredes anticlinales y periclinal externa, y relieve de los límites celulares), a los que este estudio suma la presencia y forma de los silicofitolitos.

La forma de las células epidérmicas puede ser variable: más o menos isodiamétricas, poligonales o alargadas, pero siempre el lado mayor está dispuesto paralelo al eje mayor del fruto, confirmando lo propuesto por Goetghebeur (1984) y Goetghebeur \& Coudijzer (1985), que dice "el carácter más importante para separar Bulbostylis de Fimbristylis es la superficie del fruto, en Fimbristylis las células se ubican con su eje mayor perpendicular al eje del fruto, mientras que en Bulbostylis están en forma paralela".

La pared anticlinal de las células epidérmicas presenta ondulación variable, en varias especies es lisa, carácter predominante en el grupo 1. Prata et al. (2008) mencionan que la pared en la mayoría de los casos es recta, pero el análisis que realizó es en vista superficial, no se extrajo la pared periclinal externa y sinuosa solo en siete especies, 4 de las cuales fueron estudiadas en el presente trabajo y descriptas como suavemente curvadas. Considerando la subjetividad de términos tales como curvadas o sinuosas, se plantea el uso de la terminología propuesta por Stace (1965) para epidermis pero usando descriptores para las curvas: “()", "C", "V" y " $\Omega$ ", de mayor claridad.

Bulbostylis funckii es la única especie donde sin pre-tratamientos se aprecia la pared periclinal interna del epicarpio, ya que la externa es cóncava; en la mayoría de las restantes especies la pared periclinal externa es plana a convexa y su forma final dependerá de la presencia y forma del silicofitolito. El tratamiento de extracción de la pared externa de la epidermis, permitió apreciar que estas células presentan sus paredes anticlinales internas con mayor grado de ondulación que la cara externa. La escultura terciaria depende de secreciones epicuticulares, ausente en casi todas las especies aquí estudiadas de Bulbostylis, excepto por los gránulos de cera en B. sphaerolepis.

El sílice de las plantas proviene del ácido silícico que ingresa con el agua y al final de la corriente transpiratoria, cuando el agua se evapora, precipita como silicofitolitos (Raven, 1983; Canny, 1994; Datnoff et al., 2001). El lugar de depósito de sílice es variable, en los pastos y ciperáceas típicamente se encuentra a nivel de la epidermis (Twiss et al., 1969); a nivel celular puede depositarse en tres lugares: incrustado en las paredes celulares, en el lúmen o en los espacios intercelulares (Geis, 1978; Prychid et al., 2004). Los silicofitolitos están compuestos principalmente de dióxido de Sílice $\left(\mathrm{SiO}_{2}\right)$ con impurezas de otros elementos como $\mathrm{Al}, \mathrm{Fe}, \mathrm{Mn}, \mathrm{P}, \mathrm{Cu}, \mathrm{N}$ y C (Eksambekar, 2009), algunos de estos elementos fueron registrados con el microanálisis con EDX/MEB realizado en Bulbostylis. Al mapear el silicio se pudo comprobar que este elemento se encuentra en toda la superficie de los frutos de Bulbostylis y que no hay diferencias en su distribución con respecto a la presencia o ausencia de cuerpos de sílice.

La importancia de los silicofitolitos en la familia Cyperaceae ha llevado a numerosos trabajos y múltiples clasificaciones (Metcalfe, 1971, Twiss et al., 1969; Piperno, 1988), siendo la más actual el Código Internacional de Nomenclatura de Fitolitos (ICPN WORKING GROUP, 2005). Por su claridad se destaca particularmente las revisiones realizadas por Ollendorf (1992) y Cristobal (1995), en la que los silicofitolitos de las Ciperáceas poseen forma característica de conos de ápice agudo o redondeados, psilados o de superficie lisa, con ápices individuales o múltiples.

En el estudio más reciente, Prata et al. (2008) describen los silicofitolitos con forma piramidal, cónica o globosa, este último presente solo en $B$. jacobinae y B. edwalliana (Boeck.) Prata \& M.G. López. En las 20 especies analizadas en el presente trabajo se encontraron tres formas de silicofitolitos: la particular forma de cono con superficie lisa 
previamente descripta por Piperno (1988) con las dos variantes enumeradas por Ollendorf (1992): conos de ápice puntiagudo (exclusiva de $B$. loefgrenii) y conos de ápice redondeados (todas las especies restantes del grupo 3); además se describe un tercer tipo de silicofitolito, de superficie convexa o globoso, característica que concentra a las especies del grupo 2.

\section{Conclusiones}

Por medio de la espectrometría de rayos-x se confirmó la presencia de sílice en la pared de todos los frutos de Bulbostylis analizados y mediante el análisis morfoanatómico se determinó que este elemento puede o no formar cuerpos de sílice, los cuales tienen las formas típicas para la familia: silicofitolitos globosos, en forma de conos con ápices únicos, redondeados o agudos, y ocasionalmente con ápices múltiples. La presencia o ausencia de silicofitolitos y su forma tienen valor taxonómico en el género, siendo este uno de los caracteres que permitió reunir a las especies estudiadas en tres grupos principales. El uso de caracteres micromorfológicos como la forma, superficie y estructura del epicarpio se reconocen como importantes en el diagnóstico de las especies de Bulbostylis estudiadas, y se complementan con el análisis profundo de la estructura de mesocarpio y endocarpio, los cuales influencian el diseño de la superficie.

\section{Agradecimientos}

Queremos expresar nuestro agradecimiento a la Dra. Cristina Salgado y a la Ing. Agr. Noelia Rivaldi por su colaboración en la preparación de algunos materiales para la observación en MEB y a la Universidad Nacional del Nordeste por el apoyo económico en la realización del presente trabajo.

\section{Bibliografía}

ARAÚJO, A. C. \& H. M. LONGHI-WAGNER. 1997. Anatomía foliar e micromorfología do fruto na taxonomía de Cyperus L. (Cyperaceae). Iheringia Bot. 48: 103-120.
BARTHLOTT, W. 1981. Epidermal and seed surface characters of plants: systematic applicability and some evolutionary aspects. Nor. J. Bot. 1: 345-355.

BARTHLOTT W., C. NEINHUIS, D. CUTLER, F. DITSCH, I. MEUSEL, I. THEISEN \& H. WILHELMI. 1998. Classification and terminology of plant epicuticular waxes. Bot. J. Linn. Soc. 126: 237-260.

BERTOLDI DE POMAR, H. 1975. Los Silicofitolitos: sinopsis de su conocimiento. Darwiniana 19: 173355.

BROWNING, J., K. D. GORDON-GRAY \& S. G. SMITH. 1997. Achene morphology and pericarp anatomy of the type specimens of the Australian and New Zealand species of Bolboschoenus (Cyperaceae). Austral. Syst. Bot. 10: 49-58.

CANNY M. J. 1994. What becomes of the transpiration stream?. New Phytologist 114: 341-368.

CRISTOBAL R. M. A. 1995. Nuevo sistema de análisis descriptivo para fitolitos de sílice. Pyrenae: revista de prehistòria $i$ antiguitat de la Mediterrània Occidental 26: 19-38.

DATNOFF L.E., G. H. SNYDER \& G.HKORNDÖRFER. 2001. Silicon in agriculture. Studies in plant science 8. Elsevier, Amsterdam, The Netherlands.

DENTON, M. F. 1983. Anatomical studies of the Luzulae group of Cyperus (Cyperaceae). Syst. Bot. 8: $250-262$.

EKSAMBEKAR S. 2009. Review of Phytolith Research: Scope and Applications. Korean J. Quaternary Res. 23: $1-12$

GEIS, J. W. 1978. Biogenic opal in three species of Gramineae. Ann. Bot. 42: 1119-1129.

GOETGHEBEUR, P. 1984. Studies in Cyperaceae 4. New species and a new combination in Central African Bulbostylis. Bull. Jard. Bot. Natl. Belg. 54: 91-104.

GOETGHEBEUR, P. \& J. COUDIJZER. 1984. Studies in Cyperaceae 4. New species and a new combination in Central Africa. Bull. Jard. Bot. Natl. Belg. 54: 91-104.

GOETGHEBEUR, P. \& J. COUDIJZER. 1985. Studies in Cyperaceae 5. The genus Bulbostylis in Central Africa. Bull. Jard. Bot. Natl. Belg. 55: 207-259.

GONZALEZ, A. M. \& M. G. LÓPEZ. 2010. Development and morphology of the gynoecium and nutlet in two South-American Bulbostylis (Cyperaceae) species. Flora 205: 211-220.

GONZALEZ A.M. \& M.M. ARBO. 2013. Anatomía y ontogenia de las semillas en Turnera y Piriqueta. Botanical Sciences 91: 1-18.

HEFLER, S. M. \& H. M. LONGHI-WAGNER. 2008. Análise da morfologia do fruto em espécies de Cyperus L. subg. Cyperus -Cyperaceae. Acta Bot. Bras. 22: 637-651. 


\section{G.López y A. M. Gonzalez - Frutos de Bulbostylis en las especies de América austral}

ICPN WORKING GROUP: M. MADELLA, A. ALEXANDRE \& T. BALL. 2005. International Code for Phytolith Nomenclature 1.0. Ann. Bot. 96: 253-260.

JOHANSEN, D.A. 1940. Plant microtechnique. McGraw-Hill Book Co., New York.

LINDLEY, J. 1951. Glosología o de los términos usados en botánica. Fundación Miguel Lillo (San Miguel de Tucuman), Miscelánea 15.

LÓPEZ. M. G. 2012. Citología, morfología y taxonomía del género Bulbostylis (Cyperaceae) para América Austral. Tesis. Universidad Nacional del NordesteÁrea Recursos Naturales- Facultad de Ciencias Agrarias. Corrientes. Inédita.

LÓPEZ, P. S. \& O. J. MATTHEI. 1995. Micromorfología del aquenio en especies del género Cyperus L. (Cyperaceae) Chile. Gayana Bot. 52: 67-75.

LYE, K. A. 1983. Studies in African Cyperaceae 25. New taxa and combinations in Cyperus L. Nordic. J. Bot. 3: 213-232.

LYE, K. A. 2000. Achene structure and function in Cyperaceae. In: WILSON, K.L. \& D. A. MORRISON (eds.), Monocots: Systematics and Evolution. pp. 615-628. CSIRO. Melbourne.

MEHRA, P. N. \& O. P. SHARMA. 1965. Epidermal silica cells in the Cyperaceae. Bot. Gaz. 126: 53-58.

MENAPACE, F. J. 1991. A preliminary micromorphological analysis of Eleocharis (Cyperaceae) achenes for systematic potential. Can. J. Bot. 69: 1533-1541.

MENAPACE, F. J. 1993. Achene micro-morphology as a systematic aid to the series placement of Svenson's undesignated Eleocharis (Cyperaceae) species. Rhodora 95: 214-224.

MENAPACE, F. J. 2003. Achene micromorphology of some Indian Cyperaceae V. Achene micromorphology as a possible systematic aid to the taxonomic recognition of Fimbristylis sections. Bull. Bot. Surv. India 45: 21-28.

MENAPACE, F. J. \& D. E. WUJEK. 1987. The systematic significance of achene micromorphology in Carex retrorsa (Cyperaceae). Brittonia 39: 278-283.

METCALFE, C. R. 1971. Anatomy of the Monocotyledons V. Cyperaceae. Oxford. University Press.

OLLENDORF, A L. 1992. Toward a Classification scheme of sedge (Cyperaceae) phytoliths. In: RAPP, G. Jr. \& S. C, MULHOLLAND (eds.), Phytolith systematics. Emerging issues, Advances in Archaeological and Museum Science, Vol. 1, pp. 91-111. Plenum Press, London, New York.

PARR J. F., C. J. LENTFER \& W. E. BOYD. 2001. A comparative analysis of wet and dry ashing techniques for the extraction of phytoliths from plant material. J. Archaeol. Sci. 28: 875-886.
PIPERNO, D. R. 1988. Phytolith analysis: an archaeological and geological perspective. Academic Press, San Diego.

PRATA, A. P., W. W. THOMAS \& M. D. L. WANDERLEY. 2008. Micromorfologia da superfície do aquênio em Bulbostylis Kunth (Cyperaceae). Revista Brasil. Bot. 31: 587-596.

PRYCHID, C. J., RUDALL, P. J. \& M. GREGORY. 2004. Systematics and biology of silica bodies in monocotyledons. Bot. Rev. 69:377-440.

RAGONESE, A. M., E. R. GUAGLIANONE \& C. DIZEO DE STRITTMATTER. 1984. Desarrollo del pericarpio con cuerpos de sílice de dos especies de Rhynchospora Vahl (Cyperaceae). Darwiniana 25: 27-41.

RAVEN, J. A. 1983. The transport and function of silicon in plants. Biol. Rev. 58: 179-207.

RAYMOND, C. T. \& D. E. WUJEK. 1983. Scanning electron microscopy as an aid to taxonomy of sedges (Cyperaceae: Carex). Micron Microscop. Acta 14: 271-272.

SCHUYLER, A. 1971. Scanning electron microscopy of achene epidermis in species of Scirpeae and related genera. Proc. Acad. Nat. Sci. Philadelphia 123: 29-52.

STACE, C. A. 1965. Cuticular studies as and aid to plant taxonomy. Bull. Br. Mus. Nat. Hist. (Bot.) 4: 1-78.

STANDLEY, L. 1987. Anatomical studies of Carex cuchumatensis, C. decidua, and C. hermanii (Cyperaceae) and comparisons with North American taxa of the C. acuta complex. Brittonia 39: 11-19.

STANDLEY, L. 1990. Anatomical aspects of the taxonomy of sedges (Carex, Cyperaceae). Canad. J. Bot. 68: 1449-1456.

STRONG, M. T. 2006. Taxonomy and distribution of Rhynchospora (Cyperaceae) in the Guianas, South America. Contrib. U.S. Natl. Herb. 53: 1-225.

TOIVONEN, H. \& T. TIMONEN. 1976. Perigynium and achene epidermis in some species of Carex, subg. Vignea (Cyperaceae) studied by scanning electron microscopy. Ann. Bot. Fenn. 13: 49-59.

TWISS, P. C, E. SUESS \& R.M. SMITH 1969, Morphological classification of grass phytoliths, Soil Science Society of America, Proceedings 33: 109-115.

WALTER, K. S. 1975. A preliminary study of the achene epidermis of certain Carex (Cyperaceae) using scanning electron microscopy. Michigan Botanist 14: 67-72.

WATERWAY, M. J. 1990. Systematic implications of achene micromorphology in Carex section Hymenochlaenae (Cyperaceae). Can. J. Bot. 68: 630-639.

WUJEK, D. E. \& F. J. MENAPACE. 1986. Taxonomy of Carex section Folliculatae using achene morphology. Rhodora 88: 399-403. 
WUJEK, D. E.; F. J. MENAPACE; E. A. DUFFIELD \& B. H. M. NIJALINGAPPA. 2001. Achene micromorphology of some Indian Cyperaceae. IV Achene micromorphology of selected Indian Scleria. In: CHAUCHAN, S.V. \& S. CHATURVEDI (eds.), Botanical Essays: Tribute to Professor Bahadur Singh., pp. 218-228. Printwell Publishers, Jaipur, India.
WUJEK, D. E, B. H. M. NIJALINGAPPA \& S. M. GARLITZ. 1994. Achene micromorphology of some Indian Cyperaceae. II Fimbristylis. Asian J. Pl. Sci. 6: 1-17.

Recibido el 29 de junio de 2016, aceptado el 23 de agosto de 2016. 
Anexo I: Ejemplares examinados.

B. amambayensis: PARAGUAY. Dpto. San Pedro: Rancho Laguna Blanca. 17-I- 2002, Gonzales Parini \& López 800. BRASIL. Edo. Mato Grosso do Sul: Mun. Iguatemí, About 5 km E of Iguatemí, fda. Zoller, 9-II-1994, Pedersen 15984.

B. aspera: ARGEnTINA. Prov. Corrientes: Dpto. Santo Tomé, Ea. Timbó, 1-II-1983, Schinini et al. 23580. Prov. Misiones: Dpto. San Ignacio, Colonia Chica, 24-IV-1948, Schwarz 5867. BRASIL. Edo. Paraná: Mun. Ponta Grossa, Vila Velha, Parque Estadual de Vila Velha, 9-XI-1966, Occhioni 3436. PARAGUAY. Dpto. Canindeyú: 4 km W del cruce Guaraní, ruta 10, camino a Kuruguati, 9-III-2003, López et al. 296; Dpto. Paraguarí: Piribebuy, col. Piraretá, 20-XI-1950, Sparre \& Vervoorst 302; Dpto. San Pedro: Lima, Ea. "Carumbé”, 6-X-1967, Pedersen 8512.

B. brevifolia: ARGENTINA. Prov. Corrientes: Dpto. Concepción, Ea. Buena Vista, 18-X-1972, Pedersen 10213; Dpto. Empedrado, Derqui, 26-V-1995, López \& Vanni 98; Dpto. Mburucuyá, P.N.Mburucuyá, Potrero 2 grande, 19-X- 2006, Arbo et al. 9454. Prov. Misiones: Dpto. Iguazú. Parque Nacional Iguazú $8 \mathrm{~km}$ E de Pto. de las Canoas, 18-XII-1991, Vanni et al. 2966. BRASIL. Edo. Rio Grande do Sul: Mun. Arroio dos Ratos, Faxinal, 5-XII-1979, Pedersen 12617. PARAGUAY. Dpto. Amambay: Parque Nacional Cerro Corá, camino a cerro Muralla, 21-II-1994, Krapovickas, \& Cristóbal 44923.

B. communis: ARGENTINA. Prov. Buenos Aires: Ptdo. La Plata, Isla Martín García, 6-7-IV-1928, Castellanos s.n. (CTES-372062). Prov. Catamarca: Dpto. Ambato, La Rinconada, 9 km S de Los Varela, Sierra de Graciana, 27-III-1995, Saravia Toledo et al. 12868. Prov. Chaco: Dpto. $1^{\circ}$ de Mayo, Colonia Benítez, 13-III-1993, López \& Vanni 26. Prov. Córdoba: Dpto. San Alberto, Pampa de Achala, Ea. La Trinidad P. El Estanciero, 23-II-1982, Sipowig \& Cabido 6387. Prov. Corrientes: Dpto. Alvear, Ruta 36, a $300 \mathrm{~m}$ al N del Puente Bdo. Sta Rosa, 19-VI-1981, Carnevali 4737; Dpto. Capital, Laguna Soto, 16-VII-1991, López 50. Prov. Formosa: Dpto. Estanislao del Campo, Ea. San Luis, Ossella, 29-IV-1963, Bordón 392. Prov. Santiago del Estero: Dpto. Choya, Villa La Punta, falda oriental de Sierra de Guasayán, 4-I-1979, Ulibarri 974. BRASIL. Edo. Rio Grande do Sul: Mun. Montenegro, Polo Petroquimico, 18-VIII-1977, Bueno 391. PARAGUAY. Dpto. Boquerón: 30 km SE de Loma Plata, Est. Exp. Isla Poí, 25-II-1991, Vanni et al. 2260; Dpto. Paraguarí: Chololó, 14-XI- 1969, Pedersen 9292.

B. consanguinea: ARGENTINA. Prov. Formosa: Dpto. Formosa, Guaycolec, II-1919, Jörgensen 3314. BRASIL. Edo. Goiás: Mun. Anápolis, BR-153, ca. 30 km NE of Anápolis, 28-I-1978, Pedersen 12118; Mun. Campo Alegre, Rod. BR-050, km 222, 6-II-1994, Hatschbach et al. 59885. Edo. San Pablo: Mun. Itapeva, Estaçao Ecológica de Itapeva, 28-V-1995, Souza et al. 8634. PARAGUAY. Dpto. Amambay: 25 km N de Pedro Juan Caballero, 18-IV-1995, Schinini et al. 29252 A.

B. contracta: ARGENTINA. Prov. Buenos Aires: Ptdo. Saavedra, Abra del Hinojo, 21-XII-1981, Pedersen s.n. (CTES-351808). Prov. Catamarca: Dpto. Ambato, La Rinconada, $56 \mathrm{~km}$ de Catamarca, base W de la Sierra de Graciana, 25-III-1995, Saravia Toledo et al. 12809. Prov. Córdoba: Dpto. Río Cuarto, Sierras de Achiras, 23-XII-1928, King s.n. (CTES-369882). Prov. La Rioja: Dpto. Gral. Belgrano, Dique de Olta, aledaños del lugar de ingreso del río Olta, 19-XI-1998, Biurrun \& Molina 5432. Prov. Santiago del Estero: Dpto. Ojo de Agua, Ojo de Agua (alrededores), 15-XII-1947, Balegno 1288. BRASIL. Edo. Rio Grande do Sul: Mun. Porto Alegre, Barra do Ribeiro, 14-XI-1948, Rambo 37995.

B. funckii: ARGENTINA. Prov. Córdoba: Dpto. San Alberto, Pampa de Achala, Ea. La Trinidad, 14-II1984, Cabido 6787. Prov. Tucumán: Dpto. Tafi del Valle, Valle de la ciénaga, 14 Abr. 1904, Lillo 3603 (LIL).

B. guaglianoneae: ARGENTINA. Prov. Misiones: Dpto. Apóstoles, Camino hacia el Parque Provincial de la Sierra. 23-I-2008, Keller \& Franco 4904; Ruta 14, 10 km al N de San José, 22-I-1983, Guaglianone et al. 863 .

B. hirtella: ARGENTINA. Prov. Corrientes: Dpto. Concepción, Tatacuá, 9-I-1973, Pedersen 10283; Dpto. Ituzaingó, FIPLASTO Empresa Forestal, Centro Forestal Villa Olivari, 22-VIII-1994, Barret s.n. (CTES236479); E de Ituzaingó, camino a la costa del río Paraná, 9-IX- 2005, López \& Vanni 363. BRASIL. 
Edo. Paraná: Mun. Campo Mourão, Campo Mourão, 1978, J. Marques de Lima 505; Mun. Senges, S. Antonio, 5 km ao Norte, 28-II-1972, Hatschbach 29271. Edo. Santa Catarina: Mun. Sao José, Serra da Boa Vista, 2-II-1953, Reitz 5453. PARAGUAY. Dpto. Alto Paraná: 8 km W de la Supercarretera camino a Itakirí, 9-II-2003, López et al. 270; Dpto. Amambay: Parque Nacional Cerro Corá, 14-XII-1999, Ferrucci et al. 1378; Dpto. Caaguazú, 22 km S de Caaguazú, Est. Itá Carú, 29-XII-1972, Schinini 5747 A; Dpto. San Pedro: Santa Rosa, 17 km N, ruta 3, 12-II-2003, López et al. 321.

B. jacobinae: BRASIL. Edo. Goiás: Serra Dourada,21-I-1967, Duarte 10255; Mun. Alto Paraíso de Goiás, Rod. GO-327, 5-10 km O de Alto Paraíso, 12-II-1990, Hatschbach et al. 53874; Edo. Minas Gerais: Mun. Diamantina, Ribeirão das Pedras, 14-XI-1971, Hatschbach \& Pelanda 27902. Edo. Paraná: Mun. Palmeira, 25-X-1976, Dombrowski 6694. PARAGUAY. Dpto. Amambay: Parque Nacional Cerro Corá, 2-XI-1997, Basualdo 6446.

B. junciformis: BRASIL. Edo. Paraná: Mun. Curitiba, Río Atuba, 30-I-1974, Kummrow 183; Mun. Pirai do Sul, Pirai do Sul, 16-I-1965, Hatschbach et al. 12158. Edo. San Pablo: Mun. Mogi Guaçu, Martino Prado, Reserva Biológica da Fazenda Campininha, 27-I-1981, Mantovani 47. PARAGUAY. Dpto. Amambay: Camino a Colonia Estrella, $1 \mathrm{~km} \mathrm{~W}$ del Hito 1/44, 10-XII-1997, Schinini \& Dematteis 33648; Ea. San Luis, Sierra de Amambay, cerca del límite Brasil-Paraguay, 6-III-2002, Schinini et al. 36227.

B. juncoides: ARGENTINA. Prov. Buenos Aires: Ptdo. Azul, Ea. Los Cerrillos, 10-VI-1997, D'Alfonso 2567. Prov. Catamarca:

Dpto. Ambato, Gracián, 1-I-1940, Castellanos 33474. Prov. Córdoba: Dpto. Cosquin, Sa. Grande, Dos Ríos entre río Chaves y Cuchilla Nevada, 3-III-1951, Hunziker 2718. Prov. Corrientes: Dpto. Ituzaingó, Arrocera Storti, aprox. 20 km NE Playadito, 16-XII-1981, Carnevali 4912; Dpto. Paso de los Libres, Campo Militar, General Avalos, Ea. San Pedro, 6-IV-1972, Carnevali 3204. Prov. Entre Rios: Dpto. Federación, Cantera de Chaviyú, 24-XI-1976, Troncoso et al. 1377. Prov. Jujuy: Dpto. Capital, Cerro Zapla, camino a la antena, 24-II-1988, Ahumada \& Vásquez 6066. Prov. La Pampa: Dpto. Lihuel Calel, Sierra de Lihuel Calel, 29-V-1969, Cano 4231. Prov. La Rioja: Dpto. Gral. Ángel Peñaloza, Sierra de Los Llanos, paraje llamado "Sobre el Cerro", 19-IV-1989, Biurrun 2810. Prov. Misiones: Dpto. Apóstoles; Ruta 14, 10 km E de San José, 26-II-2001, Vanni et al. 4595. Prov. Río Negro: Dpto. San Antonio, Extremo Norte de Sa. Grande, frente a Pueblo Viejo, laderas SE y S, 21-X-1979, Correa 7106. Prov. Salta: Dpto. Capital, Filo de cerros entre Castellanos y San Lorenzo, 6-10 km al E de la Quebrada San Lorenzo, 2-II-1991, Novara et al. 10149. Prov. San Luis: Dpto. Capital, Sierras de San Luis, Canutal, 21 XII-1929, Castellanos 282. Prov. Santa Fe: Dpto. Las Colonias, Aurelia, 1889, Feddersen s. n. (CTES25721). BRASIL. Edo. Paraná: Mun. Campo Mourão, Represa Rio Mourão, 17-V-1992, Hatschbach \& Noblick 57071. PARAGUAY. Dpto. Itapúa: Cnia. Fram, 2-II-1983, Lurvey 669. URUGUAY. Dpto. Cerro Largo: Av. del Lavadero, Puntas del Fraile Muerto, 8-V-1985, Del Puerto 17805.

B. loefgrenii: ARGENTINA. Misiones: Dpto. General Manuel Belgrano, Campina de Américo, 14V-2009, López \& Vanni 400. BRASIL. Edo. Goias: Mun. Mineiros, Rod. BR 060, 20-VII-1974, Hatschbach 34606. Edo. Mato Grosso do sul: Mun. Bandeirante, Rod. Br 163, 11-XI-1973, Hatschbach \& Koczicki 33041. Edo. San Pablo: Mun. Mogi Guaçu, Fazenda Campininha, 3-X-1977, Jung et al. 126. PARAGUAY. Dpto. Alto Paraná: 8 km N de Hernandarias Tapí Yupí, 8 km E de la ruta, margen derecha del río Pirá Pytá, 7-II-2003, López et al. 265; Dpto. Amambay: Colonia Yvypyté, 20-VIII-1980, Schinini \& Bordas 20506; Dpto. Caaguazú: 14 km N de Caaguazú, camino a Ihú, 27-III-1993, Schinini et al. 28113.

B. paradoxa: BRASIL. Edo. Bahia: Mun. Barra da Estiva, $8 \mathrm{~km} \mathrm{~S}$ de Barra da Estiva, camino a Ituacu: Morro do Ouro y Morro da Torre, aprox., 22-XI-1992, Arbo et al. 5706. Edo. Goiás: BR 050, 16 km N de Pires Belo (entre Catalao y Cristalina), 30-I-1990, Arbo et al. 3083. Edo. Mato Grosso: Mun. Rosário Oeste, ca. 7 km de Marzagão em direção a planalto da Serra, 7-X-1997, Souza et al. 20277. Edo. Pará: Mun. Alenquer, Estrada Cuamba (ramal a direita da Estr. Lauro Sodré), $12 \mathrm{~km}$ de Alenquer, a caminho da Fa. Capintuba, 4-XI-1987, Cid Ferreira 9405. Edo. Paraná: Mun. Balsa Nova, Barra do Rio Papagaios, 12-IX-1968, Hatschbach 19698. 


\section{G.López y A. M. Gonzalez - Frutos de Bulbostylis en las especies de América austral}

B. rugosa: ARGENTINA. Prov. Corrientes: Dpto. Empedrado, Ea. Las Tres Marías, 26-V-1995, López \& Vanni 107; Dpto. Lavalle, Barrancas del río Paraná, 25-V-1973, Schinini 6609; Dpto. Mercedes, Ea. Las Delicias, cercanías del Ayo. Itá Corá, 3-IV-2001, Tressens et al. 6699. PARAGUAY. Dpto. Cordillera: Camino entre Tobatí y Caacupé, 24-XI-2005, Schinini et al. 36692; Dpto. San Pedro: Santa Rosa, 7 km $\mathrm{N}$, ruta 3, 12-II-2003, López et al. 323.

B. scabra: ARGENTINA. Prov. Chaco: Dpto. $1^{\circ}$ de Mayo, Colonia Benítez, 24-IV-1969, Schulz 12653. Prov. Corrientes: Dpto. Bella Vista, Near the slaughter-house, some $5 \mathrm{~km} \mathrm{~S}$ of Bella Vista, 29-I-1956, Pedersen 3725; Dpto. Capital, ayo. Riachuelo y Ruta 12, 14-XII-2002, López et al. 187. Prov. Entre Ríos: Dpto. Colón, Parque Nacional El Palmar, 26-I-1973, Burkart 29202. Prov. Formosa: Dpto. Patiño, Ea. San Luis (Osella), 29-IV-1963, Bordón s.n. (CTES-410460). Prov. Misiones: Dpto. San Ignacio; Campos del Teyucuaré, 13-XI-1996, Vanni et al. 3863. BRASIL. Edo. Paraná: Mun. Laranjeiras do Sul, Rio Iguaçu, prox. a barra do Perdido, 9-XII-1968, Hatschbach, \& Guimarães 20587. Edo. Rio Grande do Sul: Mun. Alegrete, BR 290, 40 km SE de Alegrete, 5-XII-1978, Krapovickas \& Cristóbal 34163. Edo. Santa Catarina: Mun. Jaguaruna, Near Jaguaruna, 9-III-1984, Pedersen 13783. PARAGUAY. Dpto. Amambay: Parque Nacional Cerro Corá, 8-VIII-1987, Mereles 1075. URUGUAY. Dpto. Colonia: I-1917, Hauman s.n. (CTES-372105).

B. sphaerocephala: ARGENTINA. Prov. Misiones: Dpto. General Manuel Belgrano, $7 \mathrm{~km}$ W de Bernardo de Irigoyen, Campina de Américo, cerca del cementerio, 6-XII-2007, Dematteis 2708; Dpto. San Ignacio, San Ignacio, casa de H. Quiroga, 13-I-1976, Krapovickas \& Cristóbal 28712; Campos de Teyucuaré, 13 XI-1996, Vanni et al. 3864; 7 km SW de San Ignacio, en lomada cercana al río Paraná, 1-III-2004, Vanni et al. 4616. BRASIL. Edo. Paraná: Mun. Balsa Nova, São Luis do Purunã, 14-XII-1979, Hatschbach 42634. Edo. Rio Grande do Sul: Mun. San Leopoldo, San Leopoldo, 15-X-1937, Orth 2867; Edo. Santa Catarina: Mun. Lages, Parque das Pedras Brancas, 10 km SE de Lages, 19-I-1988, Krapovickas \& Cristóbal 42097. PARAGUAY. Dpto. Alto Paraná: Cnia. Laguna, camino a Itakiri, ca. 64 km NE de Hernandarias, 28-III-1993, Schinini et al. 28209; Dpto. Amambay: Pedro Juan Caballero, 21-X-1986, Pedersen 14693; Dpto. Itapúa: Trinidad, 30-X-1994, Krapovickas et al. 46157; Dpto. Paraguarí: Salto de Piraretá, 14-XI-1978, Arbo et al. 1741; Dpto. San Pedro: Distr. Lima, Ea. "Carumbé”, 30-XI-1969, Pedersen 9452.

B. sphaerolepis: ARGENTINA. Prov. Corrientes: Dpto. Berón de Astrada, Ayo. Santa Isabel y Ruta 12, 21III-1974, Schinini \& Quarín 8533; Dpto. Empedrado, Ea. Las Tres Marías, 26-V-1995, López \& Vanni 101. Prov. Jujuy: Dpto. Capital, Sierra de Zapla, 28-III-1973, Cabrera et al. 23664. Prov. Misiones: Dpto. San Ignacio, San Ignacio, casa de Horacio Quiroga, 13-I-1976, Krapovickas \& Cristóbal 28787. BRASIL. Edo. Paraná: Mun. Curitiba, Capao de Imbuia, 24-II-1975, Dombrowski 5914; Edo. Rio Grande do Sul: Mun. Quaraí, Serra Jarao, 27-XI-1979, Pedersen 12562.

B. stenocarpa: PARAGUAY. Dpto. Amambay: Ruta 3, $33 \mathrm{~km} \mathrm{~S}$ de Bella Vista, 18-IV-1995, Schinini et al. 29318; 25 km N de Pedro Juan Caballero, 18-IV-1995, Schinini et al. 29252.

B. subtilis: ARGENTINA. Prov. Chaco: Dpto. $1^{\circ}$ de Mayo, Colonia Benítez, 1-III-1932, Schulz 642. Prov. Corrientes: Dpto. Itatí, Ea. "Tuyutí", 29-IX-1972, Pedersen 10192. Prov. Misiones: Dpto. Apóstoles, Ruta 14, 10 km E de San José, 26-II-2001, Vanni et al. 4596; Dpto. Eldorado, 18 km E de Eldorado, sobre ruta 17, 24-II-2001, Vanni et al. 4548; Dpto. Iguazú, Parque Nac. Iguazú, 8 km E de Pto. De las Canoas, 18-XII-1991, Vanni et al. 2966 B. Prov. Salta: Dpto. Santa Victoria, Ruta 40, 5 km de Los Toldos hacia Lipeo, 5-XII-2005, Arbo et al. 9110. PARAGUAY. Dpto. Alto Paraná: Ea. Santa Elena, Pira Pyta, 11-x-1990, Schinini \& Caballero Marmori 27175; Dpto. Amambay: Cnia. Pindo, camino entre Itaquyry y Curuguati, Estribaciones de la Sra. de San Joaquin, 11-X-1995, Schinini \& Caballero Marmori 30181; Dpto. Itapúa: Fram, 1983, Lurvey 668. Dpto. Misiones: Ea. "La Soledad”, Santiago, 20-X-1967, Pedersen 8668. 
